\title{
Systematic approach to the development of plasma amino acid analysis by high-performance liquid chromatography with ultraviolet detection with precolumn derivatization using phenyl isothiocyanate
}

\author{
M. Hariharan*, Sundar Naga and Ted VanNoord \\ University of Michigan Medical School, Department of Psychiatry, $1150 \mathrm{~W}$. Medical Center Dr, Ann Arbor, MI 48109-0656 (USA)
}

(First received May 25th, 1993; revised manuscript received July 27th, 1993)

\begin{abstract}
A reversed-phase liquid chromatographic method for the separation of 26 phenylthiocarbamyl derivatives of amino acids in human plasma in $c a .35 \mathrm{~min}$. is described. The method used a $\mathrm{C}_{18}$ column $(150 \times 4.6 \mathrm{~mm} \mathrm{1.D.,} 3 \mu \mathrm{m})$ thermostatted at $4 \mathrm{I}^{\circ} \mathrm{C}$, and a simple multistep linear gradient of two solvents. Solvent A was $0.05 M$ sodium acetate (pH 5.1)-acetonitrile (98:2, v/v), and solvent B was water-acetonitrile $(40: 60, \mathrm{v} / \mathrm{v})$. A simple and successful approach to the optimization of the conditions for the separation of the 26 amino acid derivatives was realized. In the initial phase of development, the composition of the gradient, its timings, the column temperature, the flow-rate and the mobile phase compositions were optimized. At the end the influence of $\mathrm{pH}$ was studied, and this approach led to a clear resolution of the 26 amino acids. The method was validated by accuracy, precision, and recovery studies, by analyzing patient samples, and by comparing the quality control sample results with the classical ion-exchange method.
\end{abstract}

\section{INTRODUCTION}

Since the late $1980 \mathrm{~s}$, the classical ion-exchange chromatographic method for the analysis of amino acids (AA) has been replaced by reversedphase high-performance liquid chromatographic (HPLC) methods that are faster, more sensitive, and inexpensive. One of the two most widely used HPLC methods involves precolumn derivatization of the amino acids with phenyl isothiocyanate (PITC). There are a few reviews on AA analysis by liquid chromatography $[1,4]$. The PITC method [3-14] is very common, owing to its early

\footnotetext{
* Corresponding author.

* Presented at the 43rd Annual National Meeting of the American Clinical Chemistry Association, Washington, DC, July 1991. Clin. Chem., 37 (1991) 986.
}

commercial debut, its good sensitivity (picomolar), and the advantages of PITC over $o$-phthalaldehyde.

Recent years have seen an extensive commercialization of the analysis of AAs in physiological samples by various HPLC methods. In our view, this has contributed to a scarcity of the in-depth details necessary for a quick and successful adaptation of these methods. Although there are papers dealing with the PITC method [3-14], many workers have used the "Waters Pico Tag" system (consisting of their application-specific $\mathrm{C}_{18}$ column, dual pumps, mobile phases, gradient program, UV detector, work-station etc.) or at least the Waters column [5,6,8-10]. Only a limited number of original systems $[3,4,6,13,14]$ have been developed for the analysis of AAs in physiological samples using PITC, and all but one [6] 
have only partially succeeded in separating all 25 AAs. Few have described details of a successful systematic approach to the development of a method for the clear separation of all 25 AAs.

Our other objectives in the work were to (1) assemble an inexpensive, gradient HPLC-UV set-up that includes our own choice of analytical $\mathrm{C}_{18}$ column, (2) develop a gradient that is simple in contrast to the more elaborate methods [3,5$8,10]$, (3) develop a method that includes as many of the common AAs as possible, (4) verify if the assay should be performed under ion-pairing conditions, as tried by many early workers [6,11], (5) validate the method by analyzing physiological samples, and determining accuracy and precision data, and (6) reduce the analysis time per sample from $60 \mathrm{~min}$ or more [6,8-10].

\section{EXPERIMENTAL}

\section{Materials}

All amino acids, and the internal standard norleucine, were obtained from Sigma (St. Louis, MO, USA). Phenyl isothiocyanate was from Aldrich (Milwaukee, WI,USA). Triethylamine was from Mallinckrodt (Paris, KY, USA) and used without further purification. Sodium acetate and HPLC-grade acetonitrile were from J.T.Baker (Phillipsburg, NJ, USA). Reagent-grade water was obtained using a Milli-Q water system from Millipore (Bedford, MA, USA). The plasma ultrafiltrate was obtained using the "Centrifree" micropartition system from Amicon (Beverly, MA, USA).

\section{Apparatus}

The HPLC system consisted of two pumps (Model M45, Waters, Bedford, MA, USA), a gradient controller (Model 680, Waters), a $\mathrm{C}_{18}$ "Econosphere" column (150 mm x $4.6 \mathrm{~mm}$ I.D., $3 \mu \mathrm{m}$ ) from Alltech (Deerfield, IL, USA), a column oven (Model LC-23A) with a temperature regulator (Model LC-22A) from Bioanalytical Systems (Lafayette, IN, USA), an autosampler "Wisp" Model 710B, Waters), a UV detector (Model 655A, Hitachi, Danbury, CI, USA) with a 5-mm path-length flow-cell set at $254 \mathrm{~nm}$, and an integrator plotter (Model D-2000, Hitachi). All evaporations were done using a Speed Vac Concentrator (Model SVC 100H, Savant, Hicksville, NY, USA).

\section{Chromatographic conditions}

The PITC-AA adducts were separated using a multistep linear gradient with two solvents. Solvent $\mathrm{A}$ was $0.050 \mathrm{M}$ sodium acetate $(\mathrm{pH} 5.1)-$ acetonitrile $(98: 2, \mathrm{v} / \mathrm{v})$. Solvent B was water-acetonitrile $(40: 60, \mathrm{v} / \mathrm{v})$. Table I gives delails of the linear gradient program (flow-rate $1.2 \mathrm{ml} / \mathrm{min}$ ) used for the successful separation of the PITC derivatives.

\section{Standard solutions}

A single stock solution, containing $5 \mathrm{~m} M$ of all the 25 amino acids, was prepared in $1 \mathrm{~m} M$ hydrochloric acid made using HPLC-grade water. This standard mixture was diluted to $20,50,100,200$, 500,750 and $1000 \mu M$ concentrations, aliquotted into micro-centrifuge tubes and kept at $-80^{\circ} \mathrm{C}$. These standards are stable for $c a .1$ year. Similarly, a working internal standard solution of norleucine of $40 \mu \mathrm{M}$ concentration was prepared, and $50 \mu \mathrm{l}$ of the solution were added per $50 \mu \mathrm{l}$ of ultrafiltrate prior to derivatization.

\section{Samples}

Proper sample collection, processing, and storage are of utmost importance in this work because the concentrations of many AAs are affected by these factors [1]. Immediately after collec-

\section{TABLE I}

GRADIENT PROFILE FOR THE SEPARATION OF PITCAA ADDUCT PEAKS

\begin{tabular}{lcc}
\hline Time (min) & A (\%) & B(\%) \\
\hline 0 & 100 & 0 \\
29 & 52 & 48 \\
31 & 0 & 100 \\
43 & 0 & 100 \\
44 & 100 & 0 \\
\hline
\end{tabular}


tion, the EDTA blood was spun at $c a .1500 \mathrm{~g}$ for $15 \mathrm{~min}$. A $500-\mu \mathrm{l}$ aliquot of separated plasma was pipetted into an Amicon Centrifree micropartition system and ultracentrifuged at $1500 \mathrm{~g}$ for 30 min. The ultrafiltrate obtained was stored at $-80^{\circ} \mathrm{C}$ until analysis (ca. 1 month).

\section{Derivatization}

A 50- $\mu$ l volume of the ultrafiltrate (or the aqueous standard) and $50 \mu \mathrm{l}$ of the $40 \mu M$ solution of the internal standard, norleucine, were pipetted into a micro-centrifuge tube, and the mixture was vacuum-dried using the Speed Vac concentrator. The procedure was repeated after adding and vortex-mixing with $10 \mu 1$ of a solution of methanol-water-triethylamine $(2: 1: 1, \mathrm{v} / \mathrm{v})$. The AAs were derivatized using $20 \mu \mathrm{l}$ of a solution of ethanol, water, triethylamine, and PITC (7:1:1:1, v/ v). The tubes were vortex-mixed and allowed to stand at room temperature for $10 \mathrm{~min}$. The tubes were vacuum-dried using the Speed Vac Concentrator. It took $\mathrm{ca} .1 \mathrm{~h}$ to vacuum-dry 12 tubes. The residue was reconstituted in $500 \mu \mathrm{l}$ of mobile phase A adjusted to $\mathrm{pH} 7.5$, and $15 \mu \mathrm{l}$ were injected into the HPLC system.

\section{Method development}

Cohen and Strydom successfully separated 25 amino acids in $c a$. $60 \mathrm{~min}$ on a $3 \mu \mathrm{m}$, reversedphase $\mathrm{C}_{18}$ column $(300 \mathrm{~mm} \times 3.9 \mathrm{~mm}$ I.D.) $[6,12]$ with a theoretical plate number of $c a$. 22000 . We began our separation work by choosing the Econosphere $\mathrm{C}_{18}$ column $(150 \mathrm{~mm} \times 4.6$ mm I.D., $3 \mu \mathrm{m}$, Alltech, Deerfield, IL, USA) with a plate count of $c a .18000$, and a gradient system of two reagents. Reagent $\mathrm{A}$ was a $0.05 \mathrm{M}$ ammonium acetate buffer of $\mathrm{pH} 6.8$, and reagent $\mathrm{B}$ was water-acetonitrile (50:50, v/v). After a series of trials involving slight changes in mobile phase composition, flow-rate, and column temperature, and different gradient programs and timings, we tentatively optimized the chromatographic conditions. Mobile phase A was ammonium acetate $(0.05 M, \mathrm{pH} 6.8)$-acetonitrile $(98: 2, \mathrm{v} / \mathrm{v})$, and mobile phase $B$ was water-acetonitrile $(40: 60, \mathrm{v} / \mathrm{v})$. The flow-rate was $1.2 \mathrm{ml} / \mathrm{min}$, and the gradient program close to that in Table I. At this stage of the separation work, $c a .70 \%$ of the 26 PITC-AA adduct peaks were clearly resolved. The real challenge of our work was reduced to the resolution of the following pairs of coeluting peaks at $\mathrm{pH}$ 6.8: glycine and aspargine, tyrosine and valine, ornithine and tryptophan, and leucine and isoleucine.

Attempts were made to separate the above pairs of amino acids by studying the influence of one of the variables while keeping all others constant. Although many moderate changes were noted with the different variables, the influence of $\mathrm{pH}$ was most dramatic and was the key to the separation of all the four pairs of peaks. When the buffer $\mathrm{pH}$ value was close to 7.0 , glycine and asparagine coeluted, with glycine following asparagine. An increase in the temperature in this $\mathrm{pH}$ range only decreased the resolution of the two AAs. However, when the buffer $\mathrm{pH}$ was lowered to $c a .5 .5$, the order of elution reversed to asparagine first and glycine second. Further lowering of the $\mathrm{pH}$ below 5.5 increased the separation between the two peaks. An increase in temperature further increased this separation at low $\mathrm{pH}$. Changes in gradient timings did not have any significant effect on the resolution of the two pcaks.

When the buffer $\mathrm{pH}$ value was close to 5.2 , the tyrosine and valine peaks were very clearly separated. Temperature changes did not have any significant effect on the PITC-AA adduct peaks at lower $\mathrm{pH}$ values. Similar improved resolution was noted between tryptophan and ornithine at lower buffer $\mathrm{pH}$ values and without much temperature effect. The drawbacks of the lower $\mathrm{pH}$ value for the work was that the late-eluting reagent peaks coeluted with leucine or isoleucine or the internal standard, norleucine. However, a slight change in the linear gradient timings moved the late-eluting reagent peaks sufficicntly, and leucine and isoleucine eluted well before the reagent peak. Because a buffer of $\mathrm{pH} 5.1$ better served the separation of the AAs, the mobile phase buffer was changed to a mixture of acetic acid and sodium acetate, and the column temperature was optimized to $41^{\circ} \mathrm{C}$.

At least two different groups $[13,14]$ have studied the influence of buffer $\mathrm{nH}$ on the resolution of 
the peaks in this assay method. Both groups initially studied the separation of the PITC-AA adduct peaks using a series of buffers in the $\mathrm{pH}$ range 5.0-7.6. They optimized the buffer $\mathrm{pH}$ while keeping constant all other variables, such as analytical column temperature, gradient program, mobile phase composition, and flow-rate. This optimized buffer did not provide complete separation of all the 25 peaks, and attempts were made by the two groups to improve the resolution of the peaks by changing other variables. In contrast, we initially tried to resolve as many of the peaks by varying the gradient program, mobile phase composition, flow-rate, flow-cell dimensions, and column temperature, and at the end we optimized the buffer $\mathrm{pH}$. It seems that our approach was better in that we resolved 26 peaks in ca. $35 \mathrm{~min}$, as compared with 17 or 20 peaks by the two groups. The $\mathrm{pH}$ (5.1) of our buffer is different from almost all others [3-14] $(\mathrm{pH} \mathrm{6.5-6.8)}$ in this area of work, and this perhaps could partly be due to differences in the nature of the $\mathrm{C}_{18}$ packing materials used.

\section{RESULTS AND DISCUSSION}

Fig. 1 is a chromatogram of a plasma pool ultrafiltrate carried through the derivatization process. Fig. 2 shows a chromatogram of an underivatized protein-free filtrate at $254 \mathrm{~nm}$, confirming that there are no chromophores due to endogenous substances in the plasma ultrafiltrate at $254 \mathrm{~nm}$. Table 11 gives the retention times of the PITC adducts with 35 different AAs. Table. III gives details of the precision data for the method using a normal patient sample pool. The mean interassay coefficient of variation (C.V.) (n $=7$ ) for PITC-AA adducts is $6.9 \%$. The data compare quite well with literature reports $[4,9,10]$. The C.V. data for cystine and tryptophan are somewhat higher because of their wellknown instability [1]. Also, the low concentrations of aspartic acid, hydroxyproline, and tryptophan exaggerate their C.V. for the method. Table IV gives details of our recovery studies for 25 amino acids (cystine omitted) by adding 20, 50, 100 , and $200 \mu M$ of the standards to four differ-

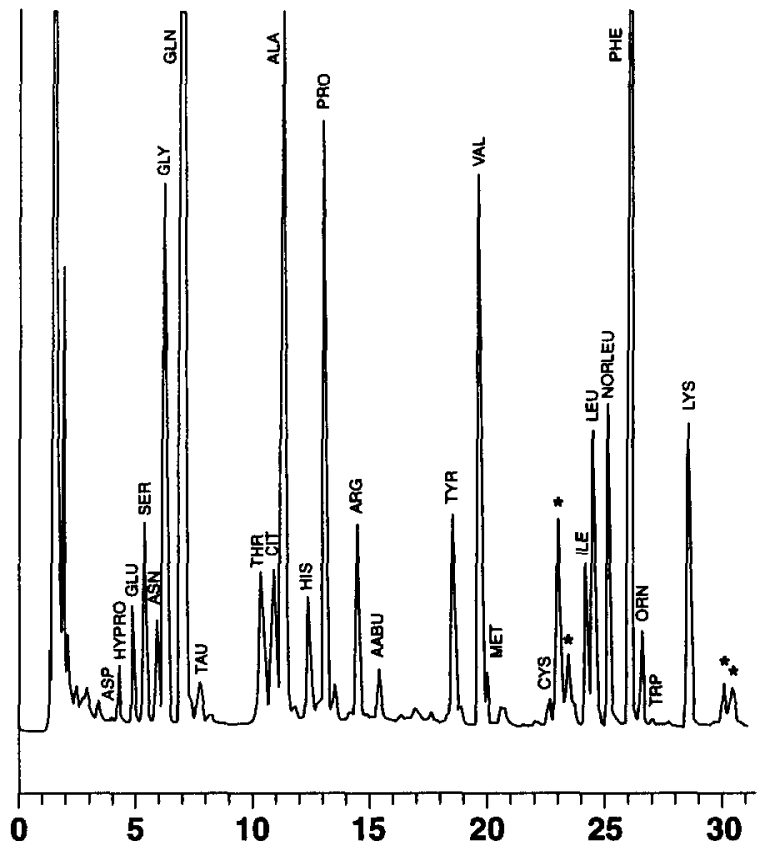

Fig. 1. HPLC separation of the PITC derivatives of 25 amino acids present in a human plasma after oral intake of "Aspartame". Reagent peaks are marked by asterisks.

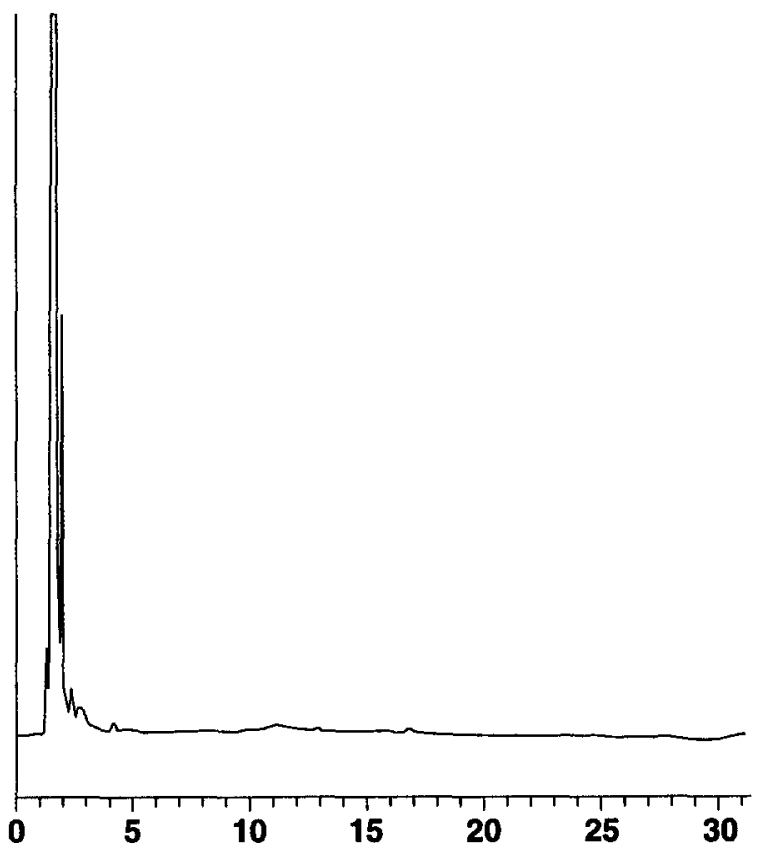

Fig. 2. Chromatogram of an underivatized protein-free ultrafiltrate of a normal human plasma (no absorption by endogenous compounds) 
TABLE II

RETENTION TIMES FOR THE PITC-AA ADDUCT PEAKS

\begin{tabular}{|c|c|}
\hline Amino acid & $\begin{array}{l}\text { Relative retention } \\
\text { time, } k^{\prime}\end{array}$ \\
\hline Aspartic acid (ASP) & 1.79 \\
\hline Hydroxyproline (HPRO) & 2.14 \\
\hline Glutamic acid (GLU) & 2.45 \\
\hline Serine (SER) & 2.94 \\
\hline Aspargine (ASN) & 3.32 \\
\hline Glycine (GLY) & 3.56 \\
\hline Glutamine (GLN) & 4.14 \\
\hline Hydroxyserine (HSER) & 4.37 \\
\hline Taurine (TAU) & 4.51 \\
\hline$\alpha$-Aminoadipic acid (AAAA) & 6.28 \\
\hline Threonine (THR) & 6.62 \\
\hline B-Alanine (BALA) & 6.71 \\
\hline Citrulline (CIT) & 6.96 \\
\hline Alanine (ALA) & 7.20 \\
\hline Methioninesulphone (METSO2) & 7.61 \\
\hline Histidine (HIS) & 7.91 \\
\hline Proline (PRO) & 8.43 \\
\hline B-Aminobutyric acid (BABA) & 8.88 \\
\hline 1-Methylhistidine (1-MH) & 9.39 \\
\hline Arginine (ARG) & 9.39 \\
\hline$\Gamma$-Aminobutyric acid(GABA) & 9.44 \\
\hline Ethanolamine (EtOHNH2) & 9.64 \\
\hline$\alpha-\Lambda$ minobutyric acid (AABA) & 10.14 \\
\hline Tyrosine (TYR) & 12.44 \\
\hline Valine (VAL) & 13.22 \\
\hline Methionine (MET) & 13.47 \\
\hline Cystine (CYS) & 15.31 \\
\hline Isoleucine (ILE) & 16.45 \\
\hline Leucine (LEU) & 16.66 \\
\hline Norleucine (NORLEU) & 17.14 \\
\hline Hydroxylysine (HYLYS) & 17.27 \\
\hline Phenylalaine (PHE) & 17.79 \\
\hline Ornithine (ORN) & 18.15 \\
\hline Tryptophan (TRP) & 18.46 \\
\hline Lysine (LYS) & 19.59 \\
\hline
\end{tabular}

ent aliquots of the same normal pool that was earlier used as a quality control sample in the work. The average recovery of the amino acids was $99.9 \%$. We found that the assay is linear up to $2 \mathrm{mmol}$. The detection limit of the assay is $c a$. 1 pmol when the signal-to-noise ratio is $5: 1$, and any concerns about this claim [4] appear invalid.
We validated the method by analyzing plasma samples from liver disease patients on oral hyperalimentation (Table V) to determine the absorption rate as a function of time, and samples from patients who were orally given "Aspartame" (Table VI), an experiment useful in determining its effect on the transport of AAs across the bloodbrain barrier [15].

Some of the pioneering workers using the PITC method $[6,11]$ have used ion-pairing conditions in the assay by adding triethylamine to the reagent $\mathrm{A}$. The ion-pairing conditions sharpen many peaks, but many peaks coelute too [11]. The retention times of PITC derivatives often change under these conditions [11, and our unpublished results]. Without triethylamine, the retention times of peaks are highly reproducible for several assays, provided the column is in good condition. The main reasons for the poor reproduciblity of the peak retention times under ionpairing conditions are that the second and stron-

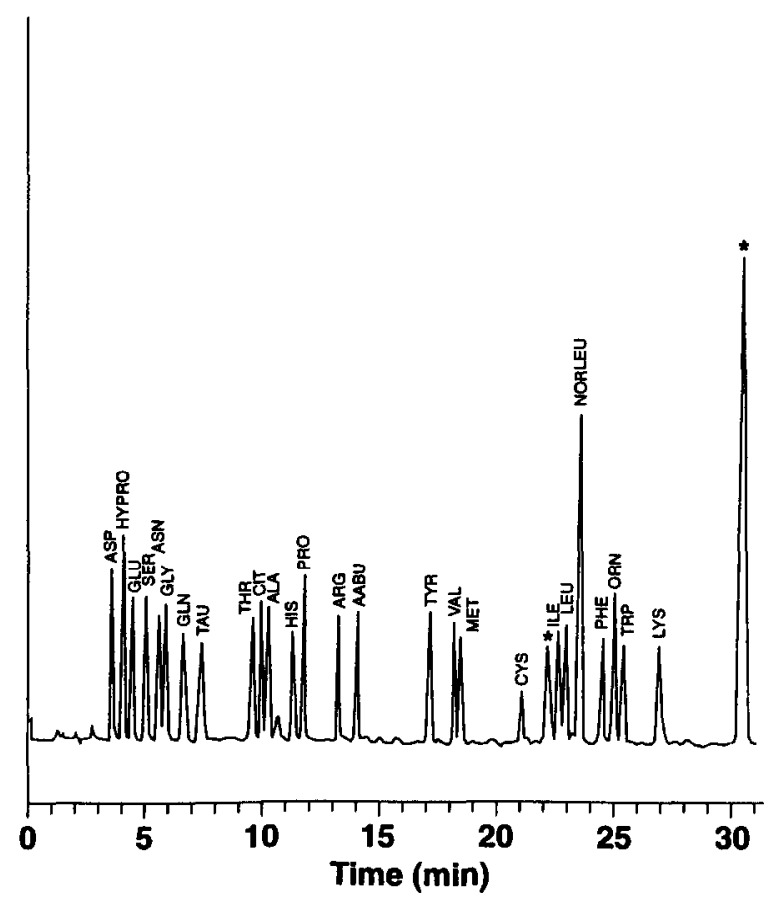

Fig. 3. HPLC separation of PITC derivatives of a standard mixture of 25 AAs ( $50 \mathrm{mmol}$ each) and norleucine ( $40 \mathrm{mmol}$ ). Reagent peaks are marked by asterisks. 
TABLE III

PRECISION DATA FOR THE PITC-AA ADDUCTS USING HUMAN PLASMA

\begin{tabular}{|c|c|c|c|c|}
\hline \multirow[t]{2}{*}{ Amino acid } & \multicolumn{2}{|l|}{ Inter-assay } & \multicolumn{2}{|l|}{ Intra-assay } \\
\hline & $\operatorname{Mean}^{a}(\mu M)$ & C.V. $(\%)$ & $\operatorname{Mean}^{\alpha}(\mu M)$ & C.V. $(\%)$ \\
\hline ASP & 3.1 & 15.6 & 3.3 & 12.6 \\
\hline HYPRO & 7.3 & 13.2 & 7.1 & 7.4 \\
\hline GLU & 21.8 & 4.2 & 22.5 & 4.4 \\
\hline SER & 63.0 & 2.3 & 59.5 & 3.2 \\
\hline ASN & 43.8 & 4.6 & 44.5 & 2.9 \\
\hline GLY & 170.0 & 5.0 & 184.0 & 3.2 \\
\hline GLN & 608.0 & 1.6 & 592.7 & 2.3 \\
\hline TAU & 31.0 & 2.2 & 26.8 & 3.1 \\
\hline THR & 87.0 & 6.9 & 71.5 & 3.4 \\
\hline CIT & 71.0 & 4.0 & 66.3 & 3.2 \\
\hline ALA & 318.0 & 2.7 & 313.0 & 3.3 \\
\hline HIS & 75.0 & 2.4 & 78.5 & 2.5 \\
\hline PRO & 182.0 & 2.1 & 178.0 & 3.1 \\
\hline ARG & 78.0 & 2.6 & 84.0 & 2.4 \\
\hline $\mathrm{AABU}$ & 12.3 & 6.5 & 9.9 & 9.0 \\
\hline TYR & 50.0 & 3.3 & 47.3 & 4.1 \\
\hline VAL & 223.0 & 7.5 & 209.0 & 1.5 \\
\hline MET & 19.2 & 13.9 & 22.8 & 5.3 \\
\hline CYS & 108.0 & 14.4 & 90.0 & 5.0 \\
\hline ILE & 64.0 & 4.1 & 61.0 & 1.9 \\
\hline LEU & 123.0 & 2.8 & 119.0 & 1.7 \\
\hline PHE & 53.0 & 2.8 & 55.0 & 2.1 \\
\hline ORN & 50.3 & 3.5 & 58.0 & 3.1 \\
\hline TRP & 5.1 & 13.0 & 4.6 & 10.2 \\
\hline LYS & 113.0 & 8.2 & 102.0 & 7.3 \\
\hline
\end{tabular}

${ }^{a} n=7$.

ger eluting mobile phase B washes out the ionpairing reagent from the column, and that it takes longer to equilibrate the column with the solvent A. Even without the addition of triethylamine, the peaks are sharp and well resolved using a 5-mm path-length UV detector flow-cell and a much stronger eluting second mobile phase with $60 \%$ acetonitrile. This is in contrast to Cohen and Strydom [6] who used a mobile phase B of water-acetonitrile-methanol $(40: 45: 15, \mathrm{v} / \mathrm{v} / \mathrm{v})$ to separate the PITC-AA adducts.

It is possible that the indiscrete $\mathrm{C}_{18}$ column that we and Ebert [11] used is not completely end- capped, and the addition of triethylamine to the mobile phase produces a higher degree of interaction between the column and the eluting PITCAA adducts (which in turn is associated with the ion-pairing agent). Such an interaction is perhaps minimal with the Waters' amino acid $\mathrm{C}_{18}$ column. In any case, care should be exercised in adding triethylamine to the mobile phases in this work.

Table VII gives the mean concentrations of AAs $(n=5)$ by the HPLC method and the ionexchange method for a normal plasma ultrafiltrate. The comparison is very good for many of 
TABLE IV

MEAN PERCENTAGE RECOVERY OF AMINO ACIDS USING SPIKED PLASMA $(n=5)$

\begin{tabular}{|c|c|c|c|c|}
\hline \multirow[t]{2}{*}{ Amino acid } & \multicolumn{4}{|c|}{ Spiked concentration $(\mu M)$} \\
\hline & 20 & 50 & 100 & 200 \\
\hline ASP & 92.3 & 92.9 & 90.9 & 87.6 \\
\hline HYPRO & 99.8 & 101.3 & 100.9 & 98.0 \\
\hline GLU & 94.8 & 93.2 & 91.4 & 89.1 \\
\hline SER & 104.0 & 100.4 & 93.3 & 89.6 \\
\hline ASN & 100.3 & 95.7 & 96.4 & 92.1 \\
\hline GLY & 113.4 & 107.3 & 97.3 & 89.5 \\
\hline GLN & 90.8 & 89.7 & 89.5 & 91.5 \\
\hline TAU & 104.8 & 99.9 & 97.6 & 93.5 \\
\hline THR & 95.4 & 94.3 & 94.1 & 87.1 \\
\hline CIT & 106.0 & 103.8 & 97.9 & 89.2 \\
\hline ALA & 105.0 & 100.0 & 88.8 & 88.9 \\
\hline HIS & 101.2 & 104.6 & 103.0 & 101.7 \\
\hline PRO & 100.4 & 86.3 & 95.1 & 93.6 \\
\hline $\mathrm{ARG}$ & 109.0 & 99.5 & 98.1 & 95.0 \\
\hline TYR & 101.3 & 101.9 & 99.9 & 97.9 \\
\hline VAL & 93.8 & 88.4 & 88.9 & 85.0 \\
\hline MET & 108.8 & 109.4 & 103.6 & 99.5 \\
\hline CYS & 114.1 & 119.2 & 120.7 & 112.4 \\
\hline ILE & 93.8 & 98.7 & 95.8 & 94.6 \\
\hline LEU & 102.0 & 103.5 & 100.7 & 99.4 \\
\hline PHE & 104.0 & 106.5 & 105.3 & 103.1 \\
\hline ORN & 112.3 & 111.9 & 105.5 & 104.5 \\
\hline TRP & 104.5 & 110.2 & 110.3 & 111.8 \\
\hline LYS & 124.2 & 113.4 & 118.7 & 115.8 \\
\hline
\end{tabular}

the amino acids, but poor for the following: glycine, proline, citruline, and methionine. The first two AAs are determined by an unconventional ratio in our ion-exchange method. The lower precisions for citruline and methionine by the ionexchange method are well known [4,5]. A similar poor precision for cystine, and the unstable nature of glutamine and asparagine, are characteristic of the PITC HPLC method.

In conclusion, our work gives greater and unique details of a systematic approach to the developmental aspect of the AA analyses by the HPLC-UV method with precolumn derivatiza-
TABLE V

PLASMA AMINO ACIDS CONCENTRATIONS FOR A LIVER DISEASE PATIENT ON ORAL ALIMENTATION

Values are in $\mu M$.

\begin{tabular}{|c|c|c|c|c|}
\hline \multirow[t]{2}{*}{ Amino acid } & \multicolumn{4}{|c|}{ Time $(\mathrm{min})$} \\
\hline & 0 & 90 & 180 & 240 \\
\hline ASP & 6.4 & 12.3 & 15.2 & 13.0 \\
\hline HPRO & 19.1 & 29.6 & 28.7 & 29.6 \\
\hline GLU & 291 & 264 & 376 & 366 \\
\hline SER & 133 & 345 & 351 & 299 \\
\hline ASN & 68 & 209 & 191 & 160 \\
\hline GLY & 299 & 418 & 392 & 385 \\
\hline GLN & 374 & 853 & 833 & 781 \\
\hline TAU & 32 & 51 & 52 & 42 \\
\hline THR & 236 & 548 & 639 & 539 \\
\hline ALA & 194 & 653 & 541 & 208 \\
\hline CIT & 43 & 60 & 69 & 71 \\
\hline HIS & 69 & 132 & 127 & 117 \\
\hline PRO & 446 & 917 & 935 & 846 \\
\hline ARG & 82 & 180 & 170 & 168 \\
\hline TYR & 185 & 314 & 339 & 341 \\
\hline VAL & 100 & 380 & 332 & 291 \\
\hline MET & 115 & 211 & 230 & 242 \\
\hline CYS & 9.6 & 9.6 & 19 & 14 \\
\hline ILE & 33 & 202 & 133 & 109 \\
\hline LEU & 59 & 313 & 199 & 146 \\
\hline PHE & 123 & 255 & 277 & 274 \\
\hline TRP & 29 & 38 & 79 & 65 \\
\hline LYS & 97 & 462 & 469 & 391 \\
\hline ORN & 92 & 144 & 198 & 203 \\
\hline
\end{tabular}

TABLE VI

HUMAN PLASMA CONCENTRATIONS OF TYROSINE AND PHENYLALANINE FOR A PATIENT ORALLY GIVEN "ASPARTAME"

\begin{tabular}{llc}
\hline Sample & TYR $(\mu M)$ & PHE $(\mu M)$ \\
\hline 1 & 37 & 42 \\
2 & 66 & 163 \\
3 & 89 & 581 \\
4 & 94 & 449 \\
5 & 109 & 393 \\
6 & 107 & 309 \\
7 & 94 & 192 \\
\hline
\end{tabular}


TABLE VII

COMPARISON OF AMINO ACID CONCENTRATIONS OF A NORMAL PLASMA OBTAINED BY THE PITC AND THE ION-EXCHANGE METHODS

Values are in $\mu M ; n=5$.

\begin{tabular}{|c|c|c|}
\hline Amino acid & $\begin{array}{l}\text { PITC } \\
\text { method }\end{array}$ & $\begin{array}{l}\text { Ion-exchange } \\
\text { method }\end{array}$ \\
\hline ASP & 3.4 & $-a$ \\
\hline HYPRO & 6.2 & $-{ }^{a}$ \\
\hline GLU & 23.3 & $\mathbf{N M}^{b}$ \\
\hline SER & 62.0 & 69 \\
\hline $\mathrm{ASN}$ & 45.5 & 46 \\
\hline GLY & 171.0 & 275 \\
\hline GLN & 622.4 & 710 \\
\hline TAU & 59.0 & 62 \\
\hline THR & 93.0 & 109 \\
\hline CIT & 60.0 & 39 \\
\hline ALA & 379.0 & 411 \\
\hline HIS & 80.0 & 75 \\
\hline PRO & 191.0 & 139 \\
\hline ARG & 78.0 & 77 \\
\hline $\mathrm{AABU}$ & 15.0 & $\mathrm{NM}^{b}$ \\
\hline TYR & 52.0 & 62 \\
\hline VAL & 234.0 & 259 \\
\hline MET & 21.0 & 36 \\
\hline CYS & 88.0 & 71 \\
\hline ILE & 62.0 & 64 \\
\hline LEU & 121.0 & $14 I$ \\
\hline PHE & 54.0 & 60 \\
\hline ORN & 45.0 & 68 \\
\hline TRP & 5.0 & $\mathrm{NM}^{b}$ \\
\hline LYS & 156.0 & 176 \\
\hline
\end{tabular}

a Too small to be measured.

$b$ Not measured.

tion using PITC. The method is characterized by its simplicity, the use of an inexpensive and indiscrete $C_{18}$ column, a simple gradient and a very short run-time, ca. $35 \mathrm{~min}$ per sample. We have validated the method with good precision, accuracy, and recovery data, and by analyzing patient plasma samples. We have compared our HPLC results with the classical ion-exchange method. Our method is simple and can be readily adapted for any laboratory with the basic equipment and some chromatographic skills.

\section{ACKNOWLEDGEMENT}

This work was supported in part by a grant from the Nutrasweet Company and from the National Institutes of Health (grant POl-NS15655 to Dr. B. W. Agranom). We are grateful to Dr. M. R. Lucey, Division of Gasteroenterology, Department of Internal Medicine, for permitting us to use data concerning one of his patients. We also thank Drs. I. G. Thoene and D. N. Buchanan, Department of Pediatrics and Communicable Diseases, for the ion-exchange method values for one of our quality control samples.

\section{REFERENCES}

1 Z. Deyl, J. Hyanek and M. Horakova, J. Chromatogr., 379 (1986) 177.

2 R. S. Ersser and J. F. Davey, Lab. Sci., 48 (1991) 59.

3 R. A. Sherwood, A. C. Titheradge and D. R. Richards, $J$. Chromatogr., 528 (1990) 293.

4 P. Furst, L. Pollack, $\Lambda$. Graser, H. Godel and P. Stehle, J. Chromatogr., 499 (1990) 557.

5 J. F. Davey and R. S. Ersser, J. Chromatogr., 528 (1990) 9. 6 S. A. Cohen and D. J. Strydom, Anal. Biochem., 174 (1988) 1.

7 L. E. Lavi and J. S. Holcenberg, J. Chromatogr., 377 (1986) 155.

8 J. L. Tedesco and R. Schafer, J. Chromatogr., 403 (1987) 299.

9 V. Fierabracci, P. Masiello, M. Novelli and E. Bergamini, $J$. Chromatogr., 570 (1991) 285.

10 R. F. Feste, J. Chromatogr., 574 (1992) 23.

11 R. F. Ebert, Anal. Biochem., 154 (1986) 431.

12 S. A. Cohen, M. Meys and T. L. Tarwin, The Pico Tag Method-A manual of advanced techniques for amino acid analysis, Millipore, Bedford, MA, WM02, 1989, Rev. 1.

13 M. Morvai, V. Fabian and I. Molnar-Perl, J. Chromatogr., 600 (1992) 87.

14 A. Guitart, P. H. Orte and J. Cacho, Analyst, 16 (1991) 399

15 R. A. Koeppe, B. L. Shulkin, K. C. Rosenpire, L. A. Shaw, A. L. Betz, T. Mangner, J. C. Price and B. W. Agranoff, $J$. Neurochem., 56 (1991) 1526. 